\title{
Manual material handling in an automotive testing department using work movement task analysis
}

\author{
Shamsul Sarip*, Zul Fazlizan Saidin, Hazilah Mad Kaidi and Mohamed Azlan Suhot \\ Razak Faculty of Technology and Informatics, UTM Kuala Lumpur, 54100, Malaysia
}

Received: 01-November-2020; Revised: 12-May-2021; Accepted: 16-May-2021

(C)2021 Shamsul Sarip et al. This is an open access article distributed under the Creative Commons Attribution (CC BY) License, which permits unrestricted use, distribution, and reproduction in any medium, provided the original work is properly cited.

\begin{abstract}
Manual material handling (MMH) has become a big concern recently in the automotive testing department. Several medical leave absenteeism was reported while bodily pain and the number of Social Security Organization (SOCSO) claimed have also increased. MMH activities involve manual movement, such as manual lifting, lowering, carrying, or even pushing and pulling loads. In this study, there are three objectives, first is to identify the risk of improper manual material handling, second to analyze the risk of manual material handling and finally to propose a manual material handling solution to the automotive testing department. To achieve the objectives, a survey with a sample population of 70 employees was conducted. Apart from that, a risk assessment was conducted to assess ten selected work activities using Work Movement Task Analysis (WMTA). The data obtained was analyzed to assist in proposing guidelines to reduce the risk of MMH activities. The goal of this study is to propose guidelines or safe work procedures on MMH to the management.
\end{abstract}

\section{Keywords}

Manual material handling, Low back pain, Musculoskeletal disorder, Work movement task analysis.

\section{Introduction}

In the automotive testing department, manual material handling $(\mathrm{MMH})$ has recently become a major issue. There have been many reports of medical leave absences, as well as a rise in the number of Social Security Organization (SOCSO) claims. A statistical report by SOCSO in Table 1 shows the increasing number of musculoskeletal diseases reported from 2012 until 2014. Manual movement is required for $\mathrm{MMH}$ activities, which include manual lifting, lowering, carrying, and even pushing and pulling loads. MMH works contribute to a large percentage of musculoskeletal disorders reports annually. It is a high-risk activity that could cause spinal injuries because it requires a high amount of energy and strength [1]. MMH can cause several diseases. During continuous weightlifting, the number of musculoskeletal mishaps can reach up to 52 percent, while pushing or pulling 13 percent, conveying stuff 10 percent, repetitive reaching movements 13 percent, and 12 percent other exercises [2]. Musculoskeletal concerns include various conditions of degenerative damage affecting muscles, ligaments, tendons, joints, fringe nerves, and veins [3, 4].

*Author for correspondence

619
The danger of back injury increases if the load is excessively heavy and wide. It is unreasonable to expect workers to always adhere to important guidelines for lifting and delivering such as keeping the stack as close as possible to the body; which causes the muscles to get tired more quickly. Furthermore, difficulty in handling can cause items to slip and cause accidents.

Furthermore, the danger of back injury increases if the task is too difficult to complete, too frequent or takes a long time and uses abnormal stances. Awkward postures or movements include bending or twisted trunk, raised arms, bent wrists, over-reaching and task involving repetitive handling. In addition, several individual factors can influence the risk of back injuries such as lack of experience, training and unfamiliarity with the job, age factors where the risk of low back disorders increases with age and with the number of years in the workplace. Incorrect $\mathrm{MMH}$ activities give rise to risks on Low Back Pain (LBP) as well as other Musculoskeletal Disorders (MSD) [5]. Also, studies have found that ergonomic awareness concerning safety and health at the workplace is still deficient [6-8]. 
The manufacturing of cars involves tests using weights or dummies for the laboratory testing phase. To test the levelling feature of the headlights, one of the tests that must be performed is to use various weights to reflect passengers and luggage weighing about $75 \mathrm{~kg}$, which is the same weight as a human. Improper handling of a dummy weight may cause the worker or laboratory technician to suffer injury. Every year, the number of employees affected by MMH continues to grow. This matter is becoming more and more worrying and needs the attention of superiors. Therefore, it is important to establish standard methods such as experimental handling technique using a dummy. Table 2 shows the weight of a multipurpose vehicle (MPV) during test conditions.

The main objective of this study is to propose guidelines of safe work procedure for weight handling to the management. There are three goals in this study: first, define the risk of excessive weight handling; second, evaluate the risk of weight handling; and third, suggest a weight handling solution to the Automotive Testing Department. This guide can be used by workers to do the job without compromising the risks they face daily in the Automotive Testing Department. Furthermore, the goal of this study is to improve worker awareness during weight handling and further reduce the effect of manual handling on workers (reducing the cases) even if it takes time to see the results.

A statistical report by SOCSO in Table 1 shows that the number of musculoskeletal diseases reported is increasing every year from 2012 until 2014 [9-11]. Table 2 shows the weight of a multipurpose vehicle (MPV) during test conditions. The maximum rear axle condition is the worst condition where it requires an additional mass of up to $600 \mathrm{~kg}$, and the workers must lift it manually.

Table 1 Summary of the number of occupational disease cases (musculoskeletal diseases)

\begin{tabular}{llll} 
Year & Male & Female & Total \\
\hline 2012 & 288 & 160 & 448 \\
\hline 2013 & 344 & 173 & 517 \\
\hline 2014 & 416 & 259 & 675 \\
\hline
\end{tabular}

Table 2 Weight during test conditions for MPV [12]

\begin{tabular}{clc}
\hline No. & Test conditions (state of loads) for MPV & Masses (kg) \\
\hline 1. & Driver only & 1560 \\
\hline 2. & Driver + front passenger & 1635 \\
\hline 3. & Driver + front passenger $+3^{\text {rd }}$ row passengers & 1778 \\
\hline 4. & All seats occupied & 2001 \\
\hline 5. & All seats occupied + luggage up to max rear axle weight & 2090 \\
\hline 6. & Driver + luggage up to max rear axle weight & 1943 \\
\hline
\end{tabular}

\section{Methodology}

Risk assessment of manual material handling was conducted using the Musculoskeletal Discomfort Form based on the complete block diagram approach as shown in Figure 1. Risk of weight handling data involved low back pain i.e., effect of weight handling, rate of occurrence, age and working experience and MSD involved type of weight used, reported cases, insurance claimed, level of awareness and knowledge of risk.

This research examined manual material handling activities in an automotive testing department by conducting a survey to 70 out of 84 technicians in the automotive testing department. Workloads in the automotive testing department depend on a per-project basis. This study covered weight/dummy handling and automotive parts. Workers in the automotive testing department come from various backgrounds (mostly from production lines) and they may carry the occupational diseases from their previous departments. Since this study is related to health, the effect of the study might take time to achieve the output.

Quantitative, qualitative inclusive study and mixed process study methods were selected. Through data collected from credible sources, the validity and reliability of the analysis are assured by the researcher conducting the MMH study. The study data collection was analyzed using quantitative SPSS software (frequency). Job Movement Activity Analysis (WMTA) was also used in this research. 


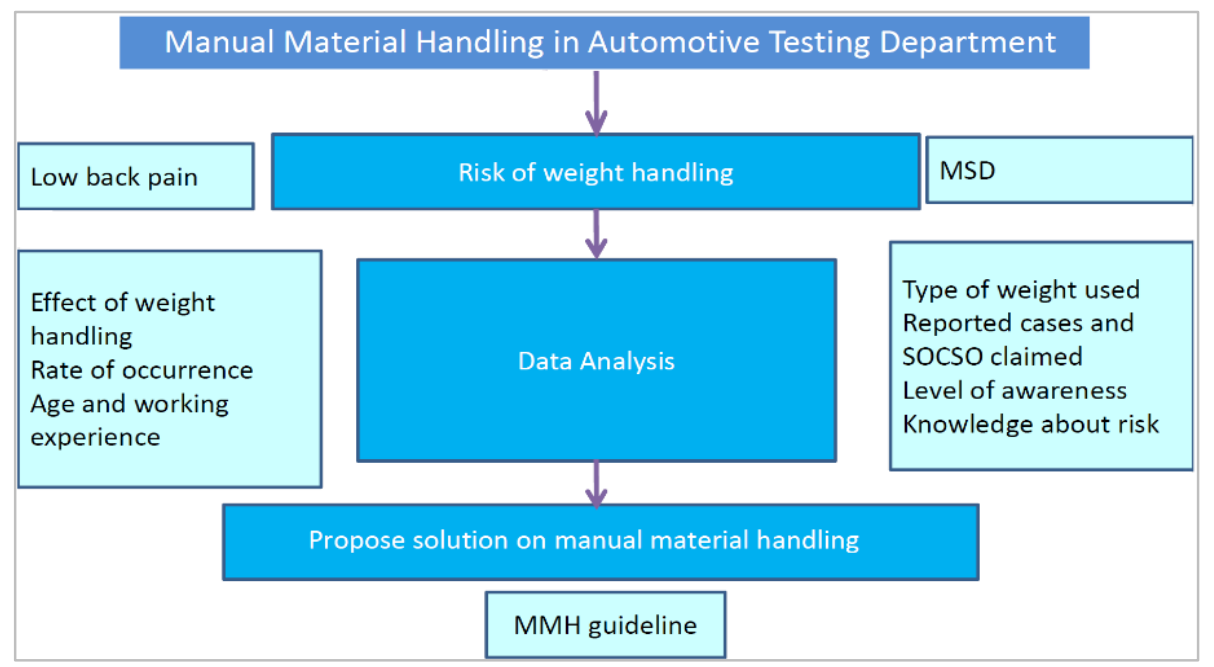

Figure 1 Block diagram approach to obtain the proposed MMH guidelines

Sample workers will be explained on the purpose of the survey in order to avoid any inconveniences and misunderstanding during the survey process. The survey will include category questions and also some of the numeric question so Likert and Satisfaction scale will take as reference in designing the questionnaires. Likert and satisfaction scales frequently use in service environment where it can provide mean values and standard deviation inventories as it helps to allow the constructive of excessive interval and/or equal interval scales that lead to meaningful statistical analysis and interpretation [13]. The questionnaires questions will start with general information of customers such as age, gender, and section and job role.

The survey questions were divided into several sections and relate to the manual material handling in their respective sections. The questions in the last part of the questionnaire relate to improvement steps. A structured questionnaire was developed. The questionnaires were divided into three different sections as follows.

Section A-Demographic data of respondents (Gender, Age, Education level, Job Role), Occupational history (Duration of employments, functional group, working hours involving manual material handling).

Section B-Manual Material Handling Risk Assessment uses Musculoskeletal Discomfort Form based on Nordic Questionnaires [14, 15]. It covers the history of trouble or pain at each body part that shows MSD symptoms.
Section C-Respondent Perspective on Manual Material Handling.

The research survey questionnaire consists of three sections, namely section A, B and C. Section A focuses on respondents' background i.e., to know the respondents' demography, which covers gender, age, height, weight, highest education, job role, years of service, workgroup, and total hours of their involvement in MMH in their daily work. Section B focuses on the MMH risk assessment where respondents need to answer 'YES' or 'NO' if they have had any problems with any body parts during the last 12 months. Nine body parts were focused, including neck, shoulders, elbows, wrists or hands, upper back, lower back, hips or thighs, knees, ankles, or feet. If they have had problems in the last 12 months, they need to answer the following question: they have been prevented from doing routine work in the last 12 months and have had problems during the last seven days. In Section C, the respondents were required to share their perspectives on MMH by answering Likert Scale scores.

\subsection{Research flow}

A research method is a research workflow to describe the sequence of work to be accomplished. The framework answers the research questions that have been set by the researcher. Meanwhile, the operating framework is a map that gives coherence to empirical inquiries, as shown in Figure 2. There are three phases had been completed during this study. 
Phase 1 is the initial process in determining the effect of $\mathrm{MMH}$ by determining the population and samples. In Phase 2, a sample population of 70 employees were the respondents to the survey conducted. A risk assessment was conducted to assess selected work activities in which ten activities were assessed using Work Movement Task Analysis (WMTA). From the data obtained, the analysis was conducted to assist in proposing a method to reduce the risk of $\mathrm{MMH}$ activities. This study also proposes safe work guidelines or procedures on weight handling to the management. Data analysis of the finding is measured using SPSS and WTMA in Phase 3. A recommendation is made at this stage.

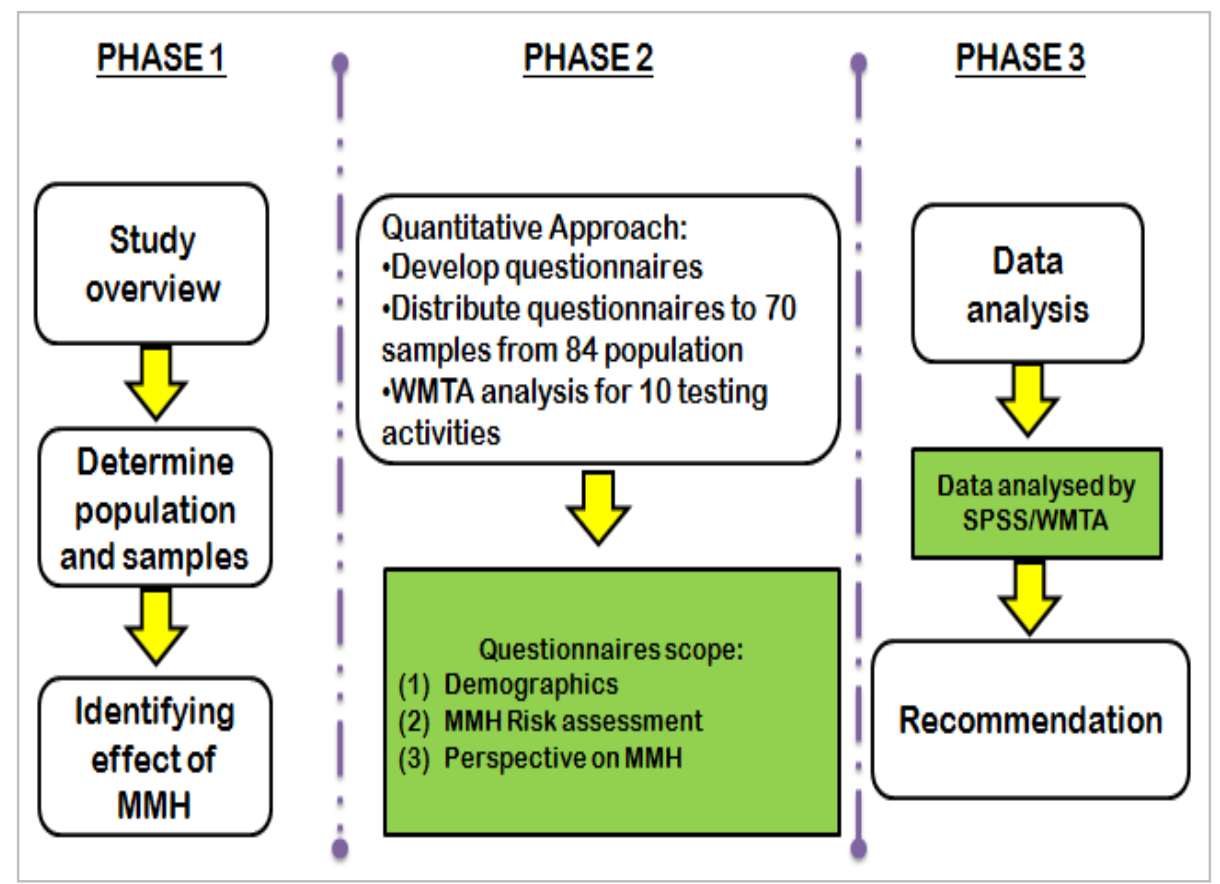

Figure 2 Structure of a research flow

2.2Work movement task analysis (WMTA) Work Movement Task Analysis (WMTA) [16, 17] is an observational tool for industrial practitioners. WMTA is a useful ergonomic tool, especially for untrained personnel to assess Work-related Musculoskeletal Disorder (WMSDs) risk factors and provide a basis for suitable intervention. Figure 3 shows the approximate position of the parts of the body referred to in Appendix. It shows the WMTA check sheet in Appendix I and WMTA score guideline in Appendix II. Limits are not sharply defined, and the specific part overlap. Respondents should decide in which part they have or have had trouble. Respondents were requested to tick in the appropriate box (one tick for each question).

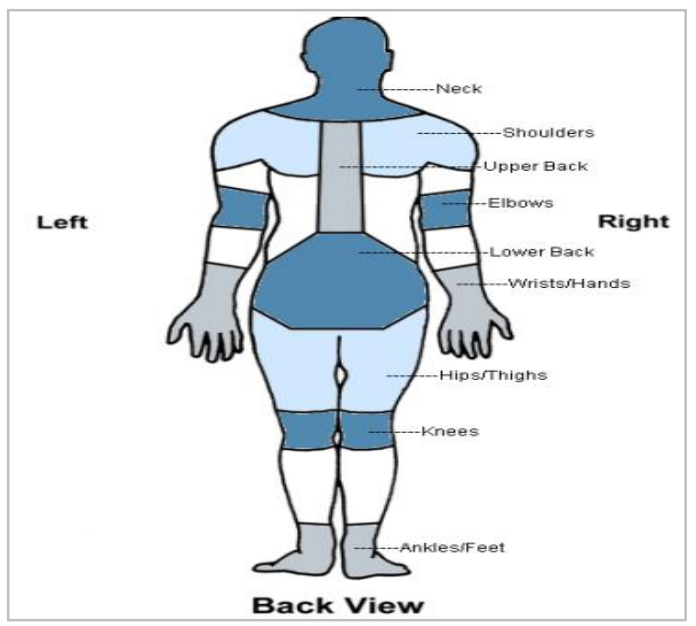

Figure 3 Position of body part [14, 15] 


\section{The research findings and discussion}

A total of 70 respondents consisting of 69 males and one female technician participated in the survey conducted for this study. Most of the respondents were from the group age of 36 to 45 years. $72 \%$ of respondents possess up to the Sijil Pelajaran Malaysia (SPM) level of education, and $42.86 \%$ already served the Automotive Department for about 6 to 10 years. Based on the survey, $44.3 \%$ of respondent claimed that they worked in MMH for about 5 to 20 hours per week, as shown in Table 3. Based on observation, there are many hazards of manual material handling in the Automotive Testing Department. Table 4 shows a respondent perspective on MMH activities and effects. The majority of respondents strongly agreed that their daily jobs involved MMH such as lifting, lowering, pulling, pushing, carrying, moving, holding or restraining objects with the highest percentage of $47.14 \%$. Furthermore, $87.14 \%$ of respondents strongly agreed that improper MMH may lead to discomfort and disability with a mean result of 4.8571 and a standard deviation of 0.38861 .

Table 3 Frequency distribution of respondents by total Hours Involved in MMH

\begin{tabular}{lll}
\hline $\begin{array}{l}\text { Total Hours Involve in Manual Material } \\
\text { Handling }\end{array}$ & Frequency & Percentage (\%) \\
\hline 20 to 40 hours (4 to 8 hours/day) & 18 & 25.7 \\
\hline 5 to 20 hours (1 to 4 hours/day) & 31 & 44.3 \\
\hline Less than 5 hours (less than 1 hour/day) & 21 & 30.0 \\
\hline Total & 70 & 100.00 \\
\hline
\end{tabular}

Table 4 Survey results for section C

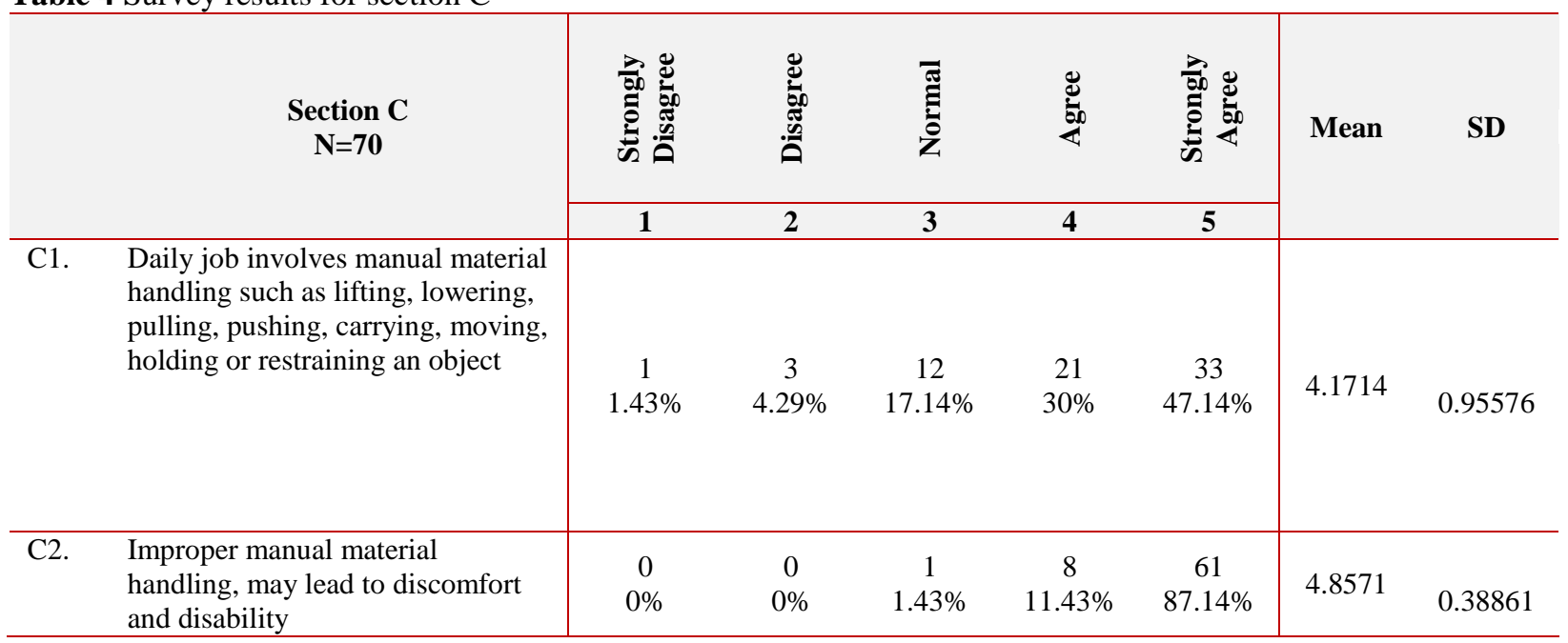

Figure 4 shows the musculoskeletal discomfort history based on the Nordic Questionnaire, which is the first part of the questionnaire that must be answered by all respondents. In the last 12 months, the highest number of discomforts was in the lower back (small of back) with a percentage of $85.71 \%$ and the lowest was in the ankles/feet with a percentage of discomfort of $21.43 \%$.

Figure 5 shows musculoskeletal discomfort history based on the Nordic Questionnaire, which is the second and third part of the questionnaire that must be answered by respondents who have musculoskeletal discomfort history in part 1 . In the last 12 months, the highest number of workers prevented from doing routine work because of problems in the lower back (small of back) was $48.57 \%$, and the lowest was in the ankles/feet with a percentage of the discomfort of $4.29 \%$.

WMTA was conducted on ten daily activities in the automotive testing department as tabulated in Figure 6. High-risk activities, which should be avoided and should be changed immediately are activities that affect the neck, which is $30 \%$, followed by the back which is $20 \%$. Shoulders and knees each contribute $10 \%$. Tolerable medium risk activities that need further investigations and modifications are activities that affect the back and shoulder which are $40 \%$ each. The environment contributes to the lowest risk at $90 \%$, which is acceptable. 
Shamsul Sarip et al.

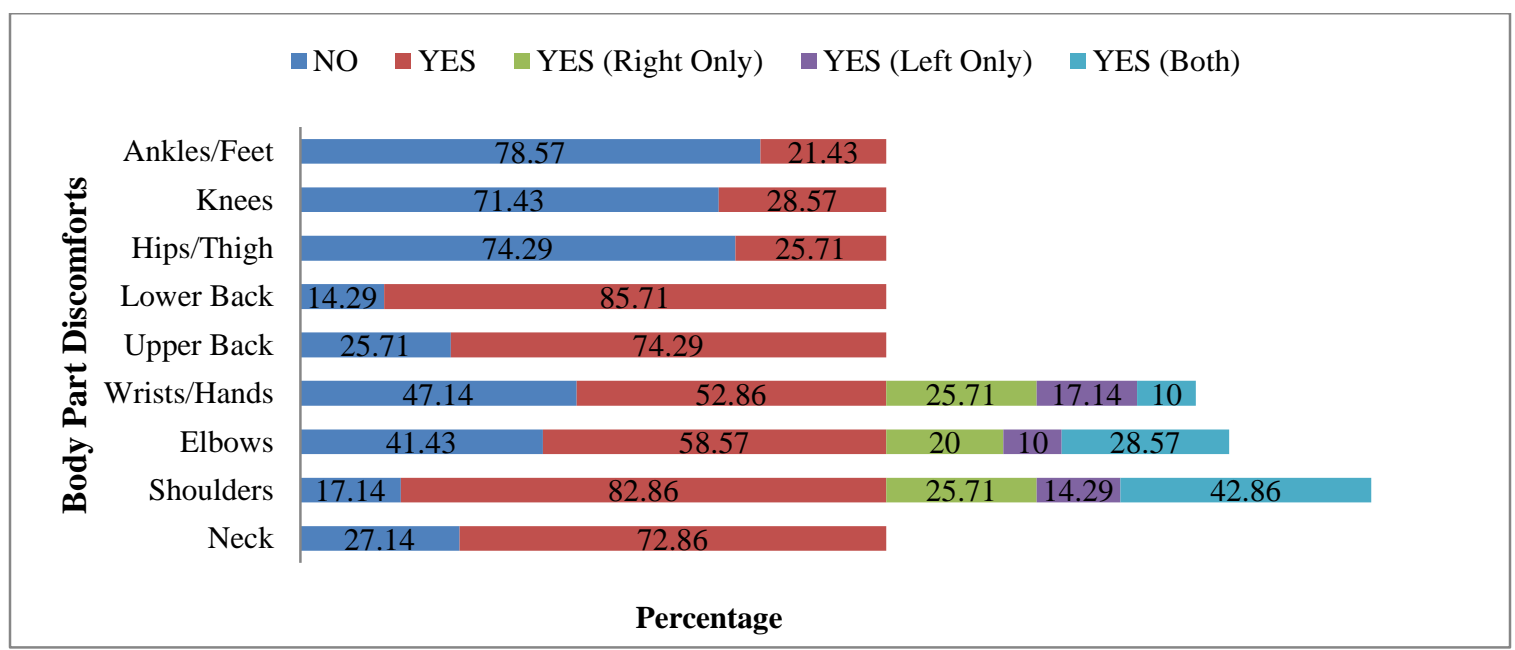

Figure 4 Bar chart of body parts discomforts in the last 12 months

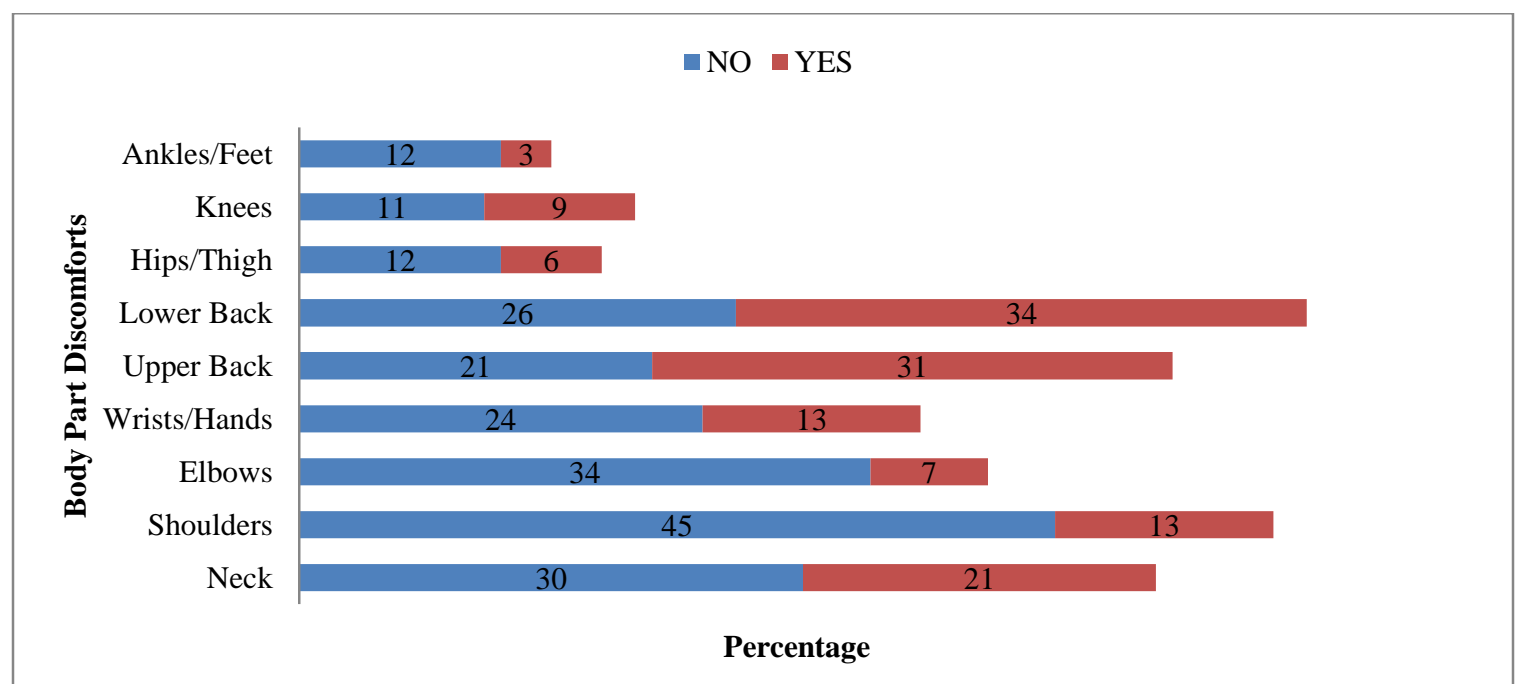

Figure 5 Bar chart of body parts discomforts in last 12 months

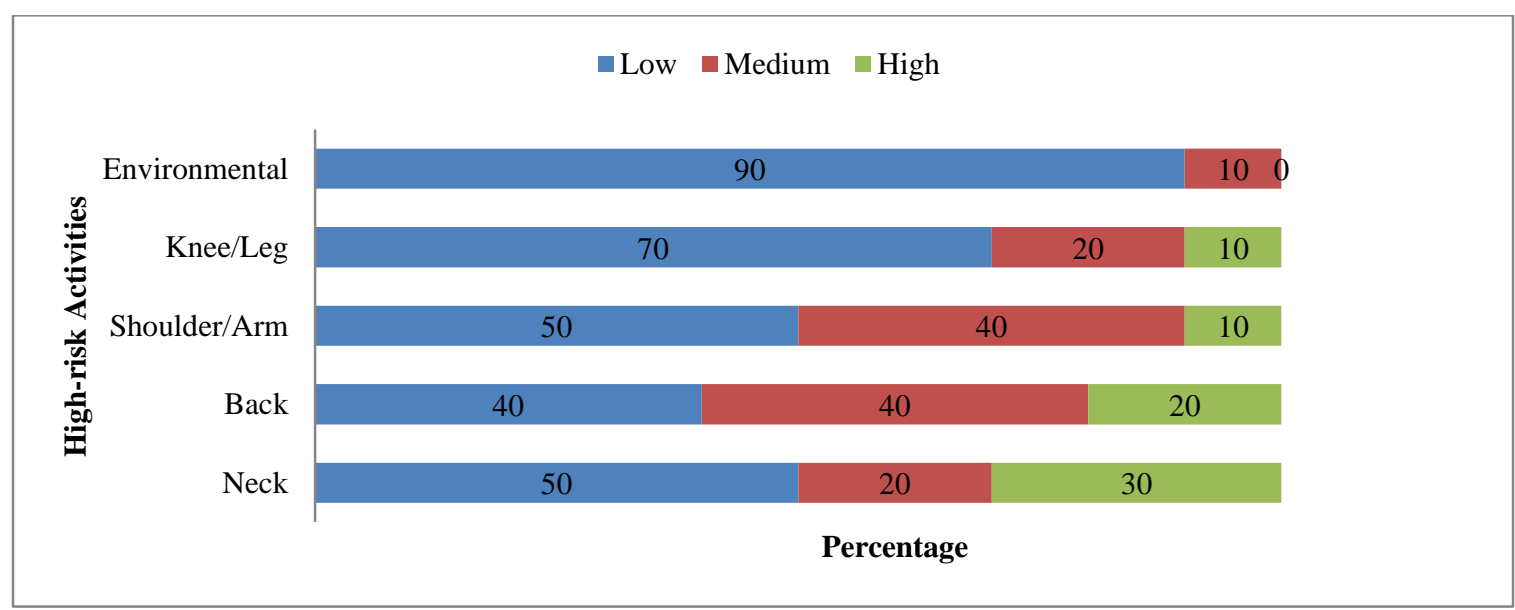

Figure 6 Bar chart percentage of WMTA risk rating 
The respondents' preference on Manual Material Handling Solution arranged from the highest mean score to the lowest mean score is shown in Figure 7. It shows the respondents perspective that 'the management should monitor workplace condition and the standard operating procedure is safe' with the highest mean score 4.8571 followed by 'lifting weight must follow guideline' with a mean score of 4.8429 and 'Engineering control such as using mechanical aid to perform a task related to manual material handling' with mean score 4.7143 .
The introduction of ergonomic concepts will help improve the efficiency and productivity of the machine, but mostly help the human operator to feel relaxed and safe [18, 19]. Ergonomics related to system and process design can help to minimize or mitigate work-related risks, as well as increase the efficiency and productivity of the business [20, 21]. Studies show that the ergonomic design of the workstation can significantly improve the operator's physiological efficiency [22-24].

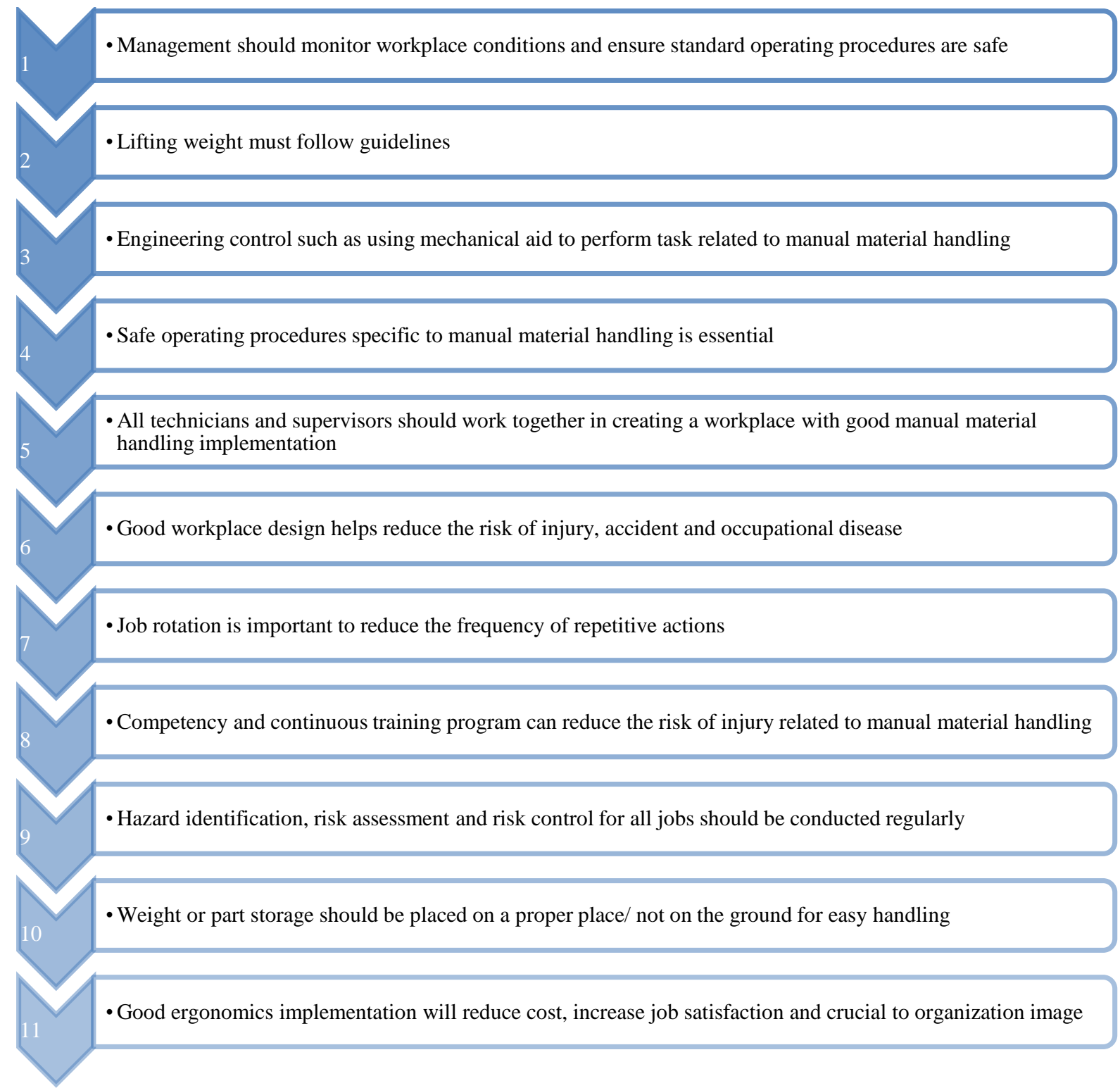

Figure 7 Respondents preference in $\mathrm{MMH}$ solution 


\section{Limitation}

Most of the workers are technicians and they come from car manufacturing factories, the medical history of the workers is not identified. The cause of the pain is due to age effects. There is no proper medical history record that causes the data collection to require more attention to the medical history of the employee. The task in the automotive testing department is based on the study and not as the main routine. It means the data taken from the respondents is a task according to the study. If less activity, then the task will be slow and take a long time to complete will affect the test results.

\section{Conclusion and future work}

The majority of the respondents strongly agreed that their daily job, with the highest percentage of $47.14 \%$ involved in MMH. $87.14 \%$ of the respondents strongly agreed that improper MMH may lead to discomfort and disability. The most affected body part in this study was found in the lower back (small of back) with a percentage of $85.71 \%$, and the lowest was the ankles/feet with a portion of discomfort of $21.43 \%$. Based on WMTA conducted, high-risk activities that should be avoided and should be changed immediately are activities that affect the neck, which is $30 \%$, followed by the back which is $20 \%$. Shoulders and knees contribute $10 \%$ each. Medium risk activities which are tolerable, but need further investigation and modification are activities affected by the back and shoulders, which is $40 \%$ each. Respondents strongly agreed that the management should monitor workplace conditions and standard operating procedure with the highest mean score of 4.8571 . Based on the response, a guideline on $\mathrm{MMH}$ is essential. Therefore, an approach on MMH for automotive testing department should be established, including guidance on weight and correct lifting techniques. Recommendations for control measures are to prevent or reduce the risk of MSD. Improvement recommendations are proposed based on the findings and blended with the Hierarchy of Risk Control as suggested by the Department of Occupational Safety \& Health (DOSH) and The National Institute for Occupational Safety and Health (NIOSH). The hierarchy of risk control which serves to protect workers from risk is also used worldwide and is referred to as standard practice in managing risk related to occupational safety. Recommendations to improve manual MMH activities are: 1) Management should monitor workplace conditions and ensure the standard operating procedures are safe, 2) Lifting weight must follow guideline, 3) Engineering control, such as using mechanical aid to perform a task related to manual material handling, 4) Safe operating procedures specific to manual material handling is essential, 5) All technicians and supervisor should work together in creating a workplace with good manual material handling implementation, 6) Good workplace design helps reduce the risk of injury, accident, and occupational disease, 7) Job rotation is vital to reduce the frequency of repetitive actions. 7) Competency and continuous training program can reduce the risk of injury related to manual material handling, 8) Hazard identification, risk assessment and risk control for all jobs should be conducted regularly, and 9) Weight or part storage should be placed in a proper place/ not on the ground for easy handling.

\section{Acknowledgment}

This work is supported by the UTM-TDR (Vote: Q.K130000.3556.07G32) grants scheme and the Networking Grant (Vot: S.K130000.7301.4X545), Universiti Teknologi Malaysia, and in collaboration with UTM Ocean Thermal Energy Centre.

\section{Conflicts of interest}

The authors have no conflicts of interest to declare. 
Appendix I Work Movement Task Analysis (WMTA) Check sheet [16]

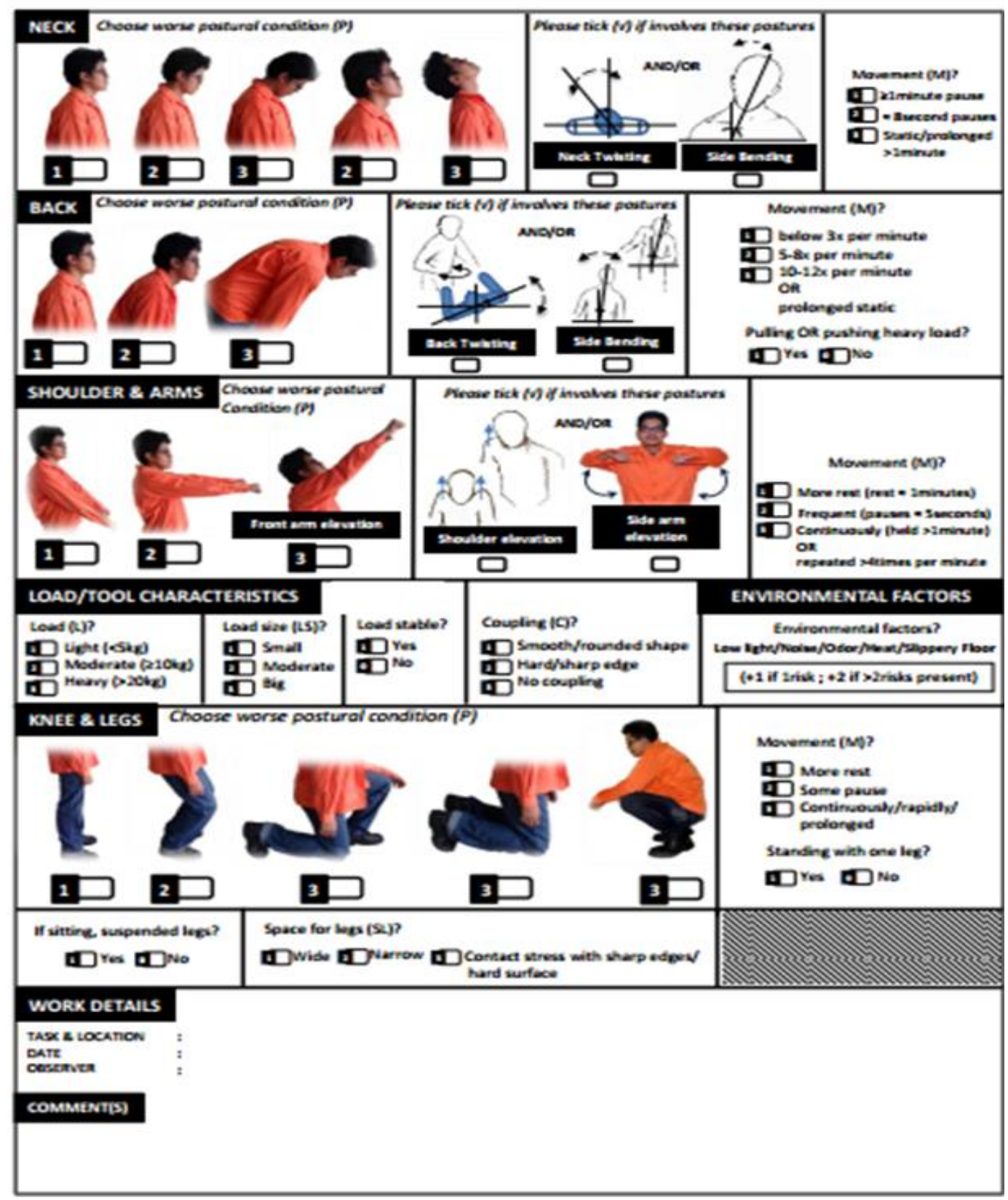


Shamsul Sarip et al.

Appendix II WMTA score guideline [16]




References

[1] Muslimah E, Pratiwi I, Rafsanjani F. Analysis of manual material handling using the NIOSH equation. Scientific Journal of Industrial Engineering. 2006; 5(2):53-60.

[2] Abdillah F. Analysis of work posture with the rapid upper limb assessment (RULA) method for fruit transport coolie workers at the ridho illahi agent, pasar johar, semarang city (Doctoral dissertation, Faculty of Public Health). Jurnal Kesehatan Masyarakat.2013; 2(1):1-10.

[3] Punnett L, Wegman DH. Work-related musculoskeletal disorders: the epidemiologic evidence and the debate. Journal of Electromyography and Kinesiology. 2004; 14(1):13-23.

[4] Ghaleb AM, Ramadan MZ, Mansour L, Al-Tamimi J, Aljaloud KS. Effect of hypoxia, safety shoe type, and lifting frequency on cardiovascular and ventilation responses. International Journal of Industrial Ergonomics. 2020.

[5] Nag PK, Hsiang S. Ergonomics in manual materials handling tasks. ICMR Bulletin. 2000; 30(8):23-31.

[6] Deros BM, Daruis DD, Basir IM. A study on ergonomic awareness among workers performing manual material handling activities. Procedia-Social and Behavioral Sciences. 2015; 195:1666-73.

[7] Piew F, Sarip S, AbdFatah AY and Kaidi HM. Business sustainability through technology management approach for construction company. International Journal of Emerging Trends in Engineering Research. 2020; 8(1.1):22-6.

[8] AWM A, SarS, AYA. F. Strategy to develop centre of accreditation of excellence (CARE) with industrialbased recognition. International Journal of Emerging Trends in Engineering Research. 2020; 8;(1.1):27-35.

[9] https://www.perkeso.gov.my/index.php/en/68report/187-annual-report. Accessed 3 January 2021.

[10] Krejcie RV, Morgan DW. Educational and psychological measurement: determining sample size for research activities. University of Minnesota, Duluth Texas A. \& M University. 1970.

[11] Hisan FN, Saifuzzaman AD, Yasak HA, Kai LC, Bani NA, Noor NM, et al. Relationship between demographic characteristics and hand grip measurement of students in UTMKL. Journal of Advanced Research in Applied Mechanics. 2017; 29(1):9-19.

[12] Day AJ. Braking of road vehicles. ButterworthHeinemann; 2014.

[13] Braunsberger K, Gates R. Developing inventories for satisfaction and likert scales in a service environment. Journal of Services Marketing. 2009; 23(4):219-25.

[14] Çakıt E. Ergonomic risk assessment using cornell musculoskeletal discomfort questionnaire in a grocery store. Age. 2019; 3(6):18-22.

[15] Kuorinka I, Jonsson B, Kilbom A, Vinterberg H, Biering-Sørensen F, Andersson G, et al. Standardized nordic questionnaires for the analysis of musculoskeletal symptoms. Applied Ergonomics. 1987; 18(3): 233-7.
[16] Shamsudin MZ, Daud MY. Development and validation of work movement task analysis: part. Research Journal of Medical Sciences. 2014; 8(2):7986.

[17] Shamsudin MZ, Daud MY, Mustafa MJ, Arshad MA, Jathin R, Mahad MS. Development and validation of work movement task analysis: part 2. ARPN Journal of Engineering and Applied Sciences. 2016; 11(10):657483.

[18] Ansari NA, Sheikh MJ. Evaluation of work posture by RULA and REBA: a case study. IOSR Journal of Mechanical and Civil Engineering. 2014; 11(4):18-23.

[19] Maldonado-Macias A, Ramírez MG, García JL, Díaz JJ, Noriega S. Ergonomic evaluation of work stations related with the operation of advanced manufacturing technology equipment: two cases of study. In XV Congreso Internacional De Ergonomia SEMAC 2009.

[20] Norhidayah MS, Mohamed NM, Mansor MA, Ismail AR. A study of postural loading in Malaysian mining industry using rapid entire body assessment. In MATEC web of conferences 2016 (pp.1-4). EDP Sciences.

[21] Tee KS, Low E, Saim H, Zakaria WN, Khialdin SB, Isa $\mathrm{H}$, et al. A study on the ergonomic assessment in the workplace. In AIP conference proceedings 2017 (pp.111). AIP Publishing LLC.

[22] Halim I, Omar AR, Saman AM, Othman I. A review on health effects associated with prolonged standing in the industrial workplaces. IJRRAS. 2011; 8(1):14-21.

[23] Heo U, Kim SJ, Kim J. Backdrivable and fully-portable pneumatic back support exoskeleton for lifting assistance. IEEE Robotics and Automation Letters. 2020; 5(2):2047-53.

[24] Widia M, Md. Dawal SZ, Yusoff N. Maximum acceptable frequency of lift for combined manual material handling task in Malaysia. PloS One. 2019; 14(5):1-13.

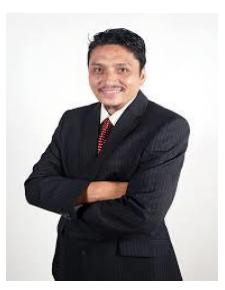

Shamsul Sarip is an Associate Professor at the Razak Faculty of Technology and Informatics, Universiti Teknologi Malaysia Kuala Lumpur. He received his Diploma in Mechanical Engineering in 1995, B. Eng in Mechanical Engineering in 1998, and M. Eng in Mechanical Engineering in 2002 from Universiti Teknologi Malaysia. His $\mathrm{PhD}$ in Mechanical Engineering from the University of Bradford, the United Kingdom in 2012. He has been involved in Engineering design, including Light Disc Brakes, MicroHydro Turbines, Ram Pumps, Ocean Current Turbines and Product Development. He is also involved in university Motorsport's activities that require him to expand his knowledge for element analysis to, Heat Transfer, Computational Fluid Dynamics and Structural Analysis. Email: shamsuls.kl@utm.my 


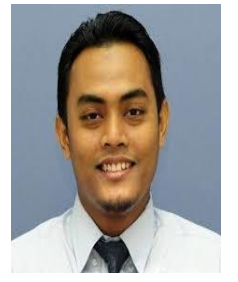

Zul Fazlizan Saidin is a Test Engineer at Perusahaan Otomobil Nasional Sdn Bhd. He has served for more than 9 years and having extensive experience in the field of vehicle testing and ergonomics.

Email: zulfazs@proton.com

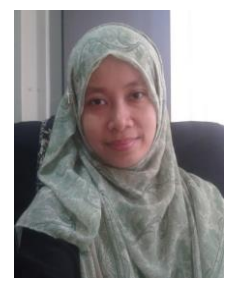

Hazilah Mad Kaidi is a senior lecturer in Razak Faculty of Technology and Informatics. She received her M.Sc. degree in Telecommunication and Information Engineering at Universiti Teknologi MARA, Malaysia, the B.Eng (Horns) in Electrical Engineering in Telecommunication and the Ph.D. degree from the Universiti Teknologi Malaysia. Her research interests include mobile and wireless communications, error Control Coding, Relay Networks, Cooperative Communications, Hybrid ARQ, Cross Layer Design, Internet of Things, and Green Technology.

Email: hazilah.kl@utm.my



Mohamed Azlan Suhot is an academic staff of the Faculty of Technology and Informatics Razak, UTM Kuala Lumpur. He received his bachelor and masters education in Materials Engineering from the University of Science Malaysia in 1996 and 2000 respectively. He then pursued and finished his $\mathrm{PhD}$ in Composite Materials from University of Southampton, United Kingdom in 2008. He has been involved in the area of Renewable Energy especially involving the installation of Sustainable Pumps and Turbines in the remote and rural area. He is also very passionate about activities involving UTM students, which also required him to be close with communities and NGOs.

Email: azlans.kl@utm.my 